\title{
Synthesis of a hemin-containing copolymer as a novel immunostimulator that induces IFN-gamma production
}

This article was published in the following Dove Press journal:

International Journal of Nanomedicine

\author{
Kazuaki Hoshi' \\ Tomohiko Yamazaki \\ Chiaki Yoshikawa ${ }^{3}$ \\ Wakako Tsugawa' \\ Kazunori Ikebukuro' \\ Koji Sode ${ }^{1,4}$
}

'Department of Biotechnology and Life Science, Graduate School of Engineering, Tokyo University of Agriculture \& Technology, Koganei, Tokyo, Japan; ${ }^{2}$ Research Center for Functional Materials, National Institute for Materials Science (NIMS), Tsukuba, Ibaraki, Japan; ${ }^{3}$ International Center for Materials Nanoarchitectonics (MANA), National Institute for Materials Science (NIMS), Tsukuba, Ibaraki, Japan; ${ }^{4}$ Joint Department of Biomedical Engineering, The University of North Carolina at Chapel Hill and North Carolina State University, Chapel Hill, NC, USA
Correspondence: Tomohiko Yamazaki Research Center for Functional Materials, National Institute for Materials Science, I-2-I Sengen, Tsukuba, Ibaraki 305-0047, Japan

Tel +8I2 98592345

Fax +8 I 29860474 I

Email yamazaki.tomohiko@nims.go.jp
Background: Hemozoin, a chemical analog of a malarial pigment, is a crystal composed of heme dimers that can act as a potent Th1-type adjuvant, which strongly induces antibody production. However, the clinical applications of malarial hemozoin have limitations due to biosafety concerns and difficulties in the manufacturing process. Based on the premise that an analog of the heme polymer might display immunostimulatory effects, a hemin-containing polymer was developed as a novel immunostimulator.

Materials and methods: To synthesize the copolymer containing hemin and $N$-isopropylacrylamide (NIPAM), this study employed a conventional radical polymerization method using 2,2'-azodiisobutyronitrile as the radical initiator; the synthesized copolymer was designated as NIPAM-hemin.

Results: NIPAM-hemin was soluble and showed no cytotoxicity in vitro. The NIPAM-hemin copolymer induced the production of interferon (IFN)- $\gamma$ and interleukin (IL)- 6 from peripheral blood mononuclear cells, although hemin and the NIPAM monomer individually did not induce the production of any cytokines. The production of IFN- $\gamma$ induced by NIPAM-hemin was independent of toll-like receptor 9 and the NLRP3 inflammasome pathway.

Conclusion: Given that NIPAM-hemin induced IL-6 and IFN- $\gamma$ production in immune cells without any cytotoxic effects, NIPAM-hemin has potential therapeutic applications as a Th1-type adjuvant.

Keywords: hemin copolymer, immunostimulator, adjuvant, radical polymerization, NIPAM, toll-like receptor 9 , T-helper 1 , inflammasome

\section{Introduction}

An adjuvant is a vaccine component that can improve the immune response to a greater extent than an antigen alone. Aluminum hydroxide crystal (alum) is the most commonly used adjuvant worldwide, but alum-containing vaccines occasionally cause local reactions such as swelling and pain at the injection site due to inflammation; in rare instances, this can lead to severe systemic symptoms. ${ }^{1}$ Thus, there is a high demand for the development of a new adjuvant that is safe, affordable, and has high adjuvanticity with a variety of antigens.

Coban et $\mathrm{al}^{2}$ reported that hemozoin, a biocrystal synthetized by the Plasmodium parasite, can act as a potent adjuvant molecule. Hemozoin is a heme crystal produced during malaria infection, and is responsible for the induction of a strong inflammatory response mediated by toll-like receptor 9 (TLR9) activation. A synthetic form of hemozoin known as $\beta$-hematin can be chemically synthesized from hemin chloride by acid catalysis, ${ }^{3}$ and also exhibits adjuvant effects. ${ }^{4,5}$ Injecting house dust mite 
allergens with alum was shown to induce Th2 responses in vivo; however, Th1 responses were induced when the allergens were co-administered with $\beta$-hematin crystals. ${ }^{6}$ These results showed that hemozoin and $\beta$-hematin can induce Th1 immune responses. However, the use of malarial hemozoin is limited by issues regarding its biosafety and mass production. Additionally, precise control of the size distribution of $\beta$-hematin by crystallization remains problematic, since the immunostimulatory effect of $\beta$-hematin depends on its crystal size. ${ }^{6}$ Accordingly, a procedure for the controlled and optimized production of uniformly sized $\beta$-hematin is needed.

Hemin binds to TLR9 and changes its conformation in a manner similar to that when bound to $\beta$-hematin. ${ }^{2}$ However, the hemin monomer shows no adjuvant effects. ${ }^{2}$ Ohto et $\mathrm{al}^{7}$ reported that the TLR9 signaling complex is formed by cooperative receptor dimerization. We predicted that the co-orientation of multiple hemin molecules is required for this conformational change in TLR9, which culminates in immune stimulation. Hemin contains two vinyl groups, and can polymerize radically with other acrylic monomers. ${ }^{8}$ Therefore, polymers containing hemin can easily be synthesized, and aspects of its molecular structure and other specific properties can be optimized.

In this study, we synthetized a novel hemin-containing copolymer and evaluated its stimulatory effects in vitro. The copolymer was synthesized using hemin and $N$-isopropylacrylamide (NIPAM), and was highly soluble in aqueous solution. This hemin-containing copolymer induced interferon (IFN)- $\gamma$ and interleukin (IL)-6 production from peripheral blood mononuclear cells (PBMCs) containing various immune cells, such as B cells, T cells, natural killer (NK) cells, macrophages, and dendritic cells. Our findings suggest that hemin-containing copolymers exhibit immunostimulatory activity, and could induce Th1-type responses, thereby acting as a potent type I adjuvant.

\section{Materials and methods}

\section{Reagents}

Hemin (ferriprotoporphyrin IX chloride) was purchased from Sigma Aldrich (St Louis, MO, USA). NIPAM and 2,2'azodiisobutyronitrile (AIBN) were obtained from Wako Pure Chemical Industries (Osaka, Japan). The pNifty-Luc plasmid, which contains the firefly luciferase gene under the nuclear factor (NF)-KB-inducible element; the transfection reagent LyoVec; the alkaline phosphatase substrate QUANTI-Blue; and lipopolysaccharide (LPS) were purchased from InvivoGen (San Diego, CA, USA). The pGL4.74[hRluc/TK] plasmid, which encodes the renilla luciferase gene, as well as a dual-luciferase reporter assay system, were purchased from Promega (Madison, WI, USA). A cell counting kit-8 (CCK-8) was used to assay cytotoxicity, and was purchased from Dojindo (Kumamoto, Japan). The phosphorothioated $\mathrm{CpG}$ oligodeoxynucleotide (ODN) 2006 PT (5'-TCGTCGTTTTGTCGTTTTGTCGTT-3') was synthesized by Eurofins Genomics (Tokyo, Japan). PolyNIPAM (molecular weight $[\mathrm{MW}]=66,400$, weight average molecular weight $[\mathrm{MW}] /$ number average molecular weight $[\mathrm{Mn}]=1.40$ ) was a kind gift from Dr Mitsuhiro Ebara, National Institute for Materials Science (NIMS).

\section{Cell culture}

The 293XL/hTLR9 and 293XL/null cell lines (InvivoGen) were cultured in high-glucose (4.5 g/L) Dulbecco's Modified Eagle's Medium (DMEM) supplemented with 10\% (v/v) fetal bovine serum (FBS), $100 \mathrm{U} / \mathrm{mL}$ penicillin, $100 \mu \mathrm{g} / \mathrm{mL}$ streptomycin, and $10 \mu \mathrm{g} / \mathrm{mL}$ blasticidin at $37^{\circ} \mathrm{C}$ in a humidified incubator containing $5 \% \mathrm{CO}_{2}$. The murine macrophage cell line $\mathrm{RAW}-\mathrm{Blue}$ (InvivoGen), which stably expresses an NF- $\mathrm{kB} /$ activator protein 1 (AP-1)-inducible secreted embryonic alkaline phosphatase (SEAP) reporter gene, was maintained in high-glucose DMEM supplemented with $10 \%(\mathrm{v} / \mathrm{v}) \mathrm{FBS}, 100 \mathrm{U} / \mathrm{mL}$ penicillin, and $100 \mu \mathrm{g} / \mathrm{mL}$ streptomycin at $37^{\circ} \mathrm{C}$ in a humidified incubator containing $5 \% \mathrm{CO}_{2}$. Another murine macrophage cell line, RAW 264 (RCB0535), was purchased from Riken BioResource Center (Tsukuba, Japan). RAW 264 cells were cultured in DMEM containing 10\% (v/v) heat-inactivated FBS, $100 \mathrm{U} / \mathrm{mL}$ penicillin, and $100 \mu \mathrm{g} / \mathrm{mL}$ streptomycin at $37^{\circ} \mathrm{C}$ in a humidified incubator containing $5 \% \mathrm{CO}_{2}$. The human-derived THP-1 monocyte cell line THP1-XBlue (InvivoGen) was cultured in RPMI 1640 supplemented with $10 \%(\mathrm{v} / \mathrm{v})$ heat-inactivated FBS, $10 \mathrm{mM}$ HEPES, $1.0 \mathrm{mM}$ sodium pyruvate, $100 \mathrm{U} / \mathrm{mL}$ penicillin, and $100 \mu \mathrm{g} / \mathrm{mL}$ streptomycin at $37^{\circ} \mathrm{C}$ in a humidified incubator containing $5 \% \mathrm{CO}_{2}$.

\section{Radical polymerization of the NIPAM- hemin copolymer}

The NIPAM-hemin copolymer was synthesized from NIPAM and hemin by conventional radical polymerization. Hemin $(1.5 \mathrm{~g}, 2.30 \mathrm{mmol}), \operatorname{NIPAM}(26.0 \mathrm{~g}, 0.230 \mathrm{~mol}), \operatorname{AIBN}(0.389 \mathrm{~g}$, $2.37 \mathrm{mmol}$ ), and pyridine $(5 \mathrm{~mL})$ were dissolved in $20 \mathrm{~mL}$ $\mathrm{N}, \mathrm{N}$-dimethylformamide. The solution was degassed and purged with argon for $20 \mathrm{~min}$. The polymerization reaction was carried out in an oil bath at $85^{\circ} \mathrm{C}$ for $48 \mathrm{~h}$. The reaction was stopped by cooling and exposing the mixture to air. Non-polymerized hemin was removed from the copolymer by extraction with methanol, and the copolymer was precipitated by adding excess diethyl ether. The precipitate was dissolved in methanol and separated using silica gel chromatography. The final product was obtained by evaporation and dissolved in sterilized deionized water for further analysis. 


\section{Characterization of the NIPAM-hemin copolymer}

Gel permeation chromatography (GPC) was conducted to determine the molecular weight of the NIPAM-hemin copolymer. The copolymer was pumped through sequential columns containing Shodex SB-804 HQ and SB-802.5 HQ resin (Showa Denko, Tokyo, Japan), and poly(sodium 4-styrenesulfonate) was used to construct a standard calibration curve.

NIPAM-hemin $(50 \mu \mathrm{g} / \mathrm{mL})$, hemin $(5 \mu \mathrm{g} / \mathrm{mL})$, polyNIPAM $(100 \mu \mathrm{g} / \mathrm{mL})$, and NIPAM $(100 \mu \mathrm{g} / \mathrm{mL})$ were each dissolved in dimethyl sulfoxide (DMSO), and absorption spectra were measured using a U-2900 spectrophotometer (Hitachi, Tokyo, Japan). To obtain infrared (IR) spectra, $\mathrm{KBr}$ pellets were prepared from dried samples of each reagent, and Fourier-transform infrared (FTIR) spectroscopy was performed using an IRTracer-100 (Shimadzu, Kyoto, Japan) with 20 scans per spectrum, a resolution of $4 \mathrm{~cm}^{-1}$, and a spectral range of $400-4,000 \mathrm{~cm}^{-1}$.

The iron content of the polymer was determined by inductively coupled plasma optical emission spectrometry (ICP-OES) on an Agilent 720-ES (Agilent Technologies, Santa Clara, CA, USA) by treating $12.5 \mathrm{mg}$ NIPAM-hemin with dilute nitric acid, sulfuric acid, and perchloric acid, followed by heating in hydrochloric acid.

\section{In vitro cytotoxicity assay}

The $293 \mathrm{XL} /$ null cells and RAW 264 cells were seeded in 96-well plates at a density of 5,000 cells/well and incubated at $37^{\circ} \mathrm{C}$ in a humidified incubator containing $5 \% \mathrm{CO}_{2}$ for $24 \mathrm{~h}$. The medium was then replaced with fresh high-glucose DMEM supplemented with $10 \%$ (v/v) heat-inactivated FBS, $100 \mathrm{U} / \mathrm{mL}$ penicillin, and $100 \mu \mathrm{g} / \mathrm{mL}$ streptomycin. NIPAMhemin copolymer was added to the medium at a final concentration of $0,0.25,0.5,0.75,1.0$, or $2.0 \mathrm{mg} / \mathrm{mL}$. After an additional 24 or $48 \mathrm{~h}$ incubation, the medium was replaced with $100 \mu \mathrm{L}$ fresh medium, and $10 \mu \mathrm{L}$ CCK-8 solution was added to each well, followed by incubation for 1 or $3 \mathrm{~h}$ at $37^{\circ} \mathrm{C}$ in a humidified incubator containing $5 \% \mathrm{CO}_{2}$. The absorbance at $450 \mathrm{~nm}\left(\mathrm{~A}_{450}\right)$ of each well was measured using a microplate reader (MTP-880Lab; Corona Electric, Ibaraki, Japan). An in vitro cytotoxicity assay for poly-NIPAM was also conducted using the same procedure described above.

\section{Stimulation of human PBMCs with NIPAM-hemin}

Commercially available frozen PBMCs were purchased from Cellular Technology Limited (Shaker Heights, OH, USA). PBMCs were thawed according to the manufacturer's instructions, and were then seeded in a 96-well plate at a density of
$1.0 \times 10^{6}$ cells/well, and stimulated with $500 \mu \mathrm{g} / \mathrm{mL}$ NIPAMhemin, hemin, NIPAM, or poly-NIPAM (MW=66,400 Da). After incubation at $37^{\circ} \mathrm{C}$ for $48 \mathrm{~h}$ in a humidified incubator containing $5 \% \mathrm{CO}_{2}$, the supernatants were collected. The levels of IFN- $\alpha$, IFN- $\gamma$, IL- 6 , and IL-1 $\beta$ secreted into the medium were determined using Ready-Set-Go! ELISA kits (eBiosciences, San Diego, CA, USA) according to the manufacturer's instructions.

\section{TLR reporter assay}

The 293XL/hTLR9 and 293XL/null cells were seeded at a density of $7.5 \times 10^{4}$ cells/well in a 96-well plate and transfected with pNifty-Luc and pGL4.74[hRluc/TK] using LyoVec transfection reagent. After culturing at $37^{\circ} \mathrm{C}$ for $24 \mathrm{~h}$, the medium was replaced with fresh DMEM containing 10\% (v/v) heat-inactivated FBS. Thereafter, NIPAM-hemin, hemin, NIPAM, or poly-NIPAM (MW=66,400 Da) were added at a final concentration of $500 \mu \mathrm{g} / \mathrm{mL}$, and the cells were incubated for an additional $24 \mathrm{~h}$ at $37^{\circ} \mathrm{C}$ in $5 \% \mathrm{CO}_{2}$. All compounds, except hemin, were dissolved in sterilized deionized water. Hemin was dissolved in DMSO. Water or DMSO without the compounds of interest were added to the culture as a negative control. CpG ODN 2006 PT was added to the medium at a final concentration of $0.5 \mu \mathrm{M}$ as a positive control. The expression level of each luciferase was determined according to the manufacturer's instructions for the dual-luciferase reporter assay system.

RAW-Blue cells and THP1-XBlue cells were seeded separately in 96-well plates at a density of $1.0 \times 10^{5}$ cells/ well and incubated for $24 \mathrm{~h}$. The medium was replaced with medium containing $10 \%(\mathrm{v} / \mathrm{v})$ heat-inactivated FBS before stimulation. NIPAM-hemin, hemin, NIPAM, or poly-NIPAM (MW=66,400 Da) were individually added to the medium at a final concentration of $500 \mu \mathrm{g} / \mathrm{mL}$, and the cells were incubated for an additional $24 \mathrm{~h}$. The supernatants were then collected, and NF-кB/AP-1 activation linked to SEAP was determined using QUANTI-Blue reagent according to the manufacturer's instructions. LPS $(500 \mu \mathrm{g} / \mathrm{mL})$ was used as a positive control.

\section{Statistical analysis}

All data are shown as the mean \pm SD. Statistical significance was evaluated using Student's $t$-test. A value of $P<0.05$ was considered statistically significant.

\section{Results Characterization of the NIPAM-hemin copolymer}

The hemin-containing copolymer NIPAM-hemin was synthesized by the radical polymerization of hemin and NIPAM 


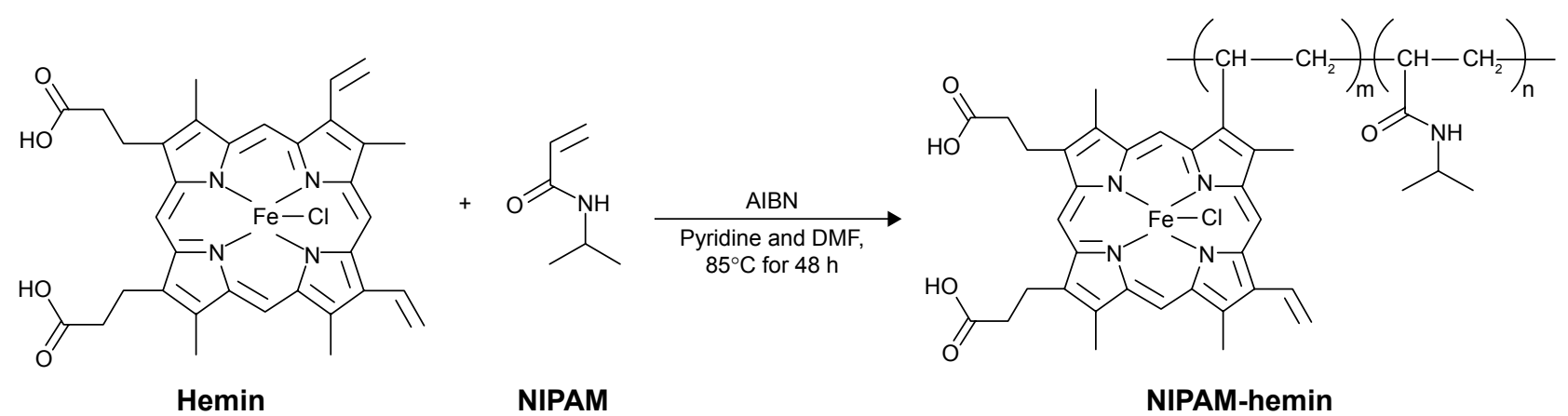

Scheme I The process of NIPAM-hemin synthesis.

Abbreviations: AIBN, 2,2'-azodiisobutyronitrile; DMF, N,N-dimethylformamide; Hemin, ferriprotoporphyrin IX chloride; NIPAM, N-isopropylacrylamide.

monomers. Scheme 1 shows the process of NIPAM-hemin synthesis. A dark-brown product was obtained after precipitation in diethyl ether and separation by silica gel chromatography. The final product was easily soluble in water, methanol, and DMSO.

The molecular weight of NIPAM-hemin was measured using GPC. The Mn and Mw of NIPAM-hemin were $1.5 \times 10^{3}$ and $3.2 \times 10^{3} \mathrm{Da}$, respectively, providing a polydispersity index of $2.1(\mathrm{Mw} / \mathrm{Mn})$.

The presence of hemin in the copolymer was confirmed by UV-vis absorption spectroscopy. Figure 1A shows the UV-vis absorption spectrum of NIPAM-hemin dissolved in DMSO. NIPAM-hemin showed a Soret peak at $398 \mathrm{~nm}$, and a peak at $570 \mathrm{~nm}$ in the Q-band region, similar to those of hemin solution. This result indicated that the copolymer contained hemin. ICP-OES measurements were conducted to estimate the proportion of hemin in the copolymer. We found that $1 \mathrm{mg}$ polymer contained $11.5 \mu \mathrm{g}$ iron. Since the number of iron atoms is equal to the number of hemin molecules, the molar ratio of hemin to NIPAM in the copolymer was estimated to be 1:37.

To confirm the presence of hemin in copolymer, the FTIR spectra were also determined (Figure 1B). The spectra of NIPAM-hemin showed peaks at $1,458 \mathrm{~cm}^{-1}, 1,547 \mathrm{~cm}^{-1}$, and $1,651 \mathrm{~cm}^{-1}$, consistent with the $-\mathrm{CH}_{3}, \mathrm{C}-\mathrm{N}$, and $\mathrm{C}=\mathrm{O}$ bonds of the NIPAM monomer, respectively. ${ }^{9}$ Compared to the NIPAM spectra, the $1,622 \mathrm{~cm}^{-1}$ band was missing from the NIPAM-hemin spectra, indicating that the $\mathrm{C}=\mathrm{C}$ bond of NIPAM was used for polymerization. These results indicated that each monomer was copolymerized using the vinyl group of each monomer. Peaks corresponding to hemin $\left(1,703 \mathrm{~cm}^{-1}\right)$ were not observed in the spectra of NIPAM-hemin because the proportion of hemin monomers in the copolymer was low compared to that of NIPAM. To
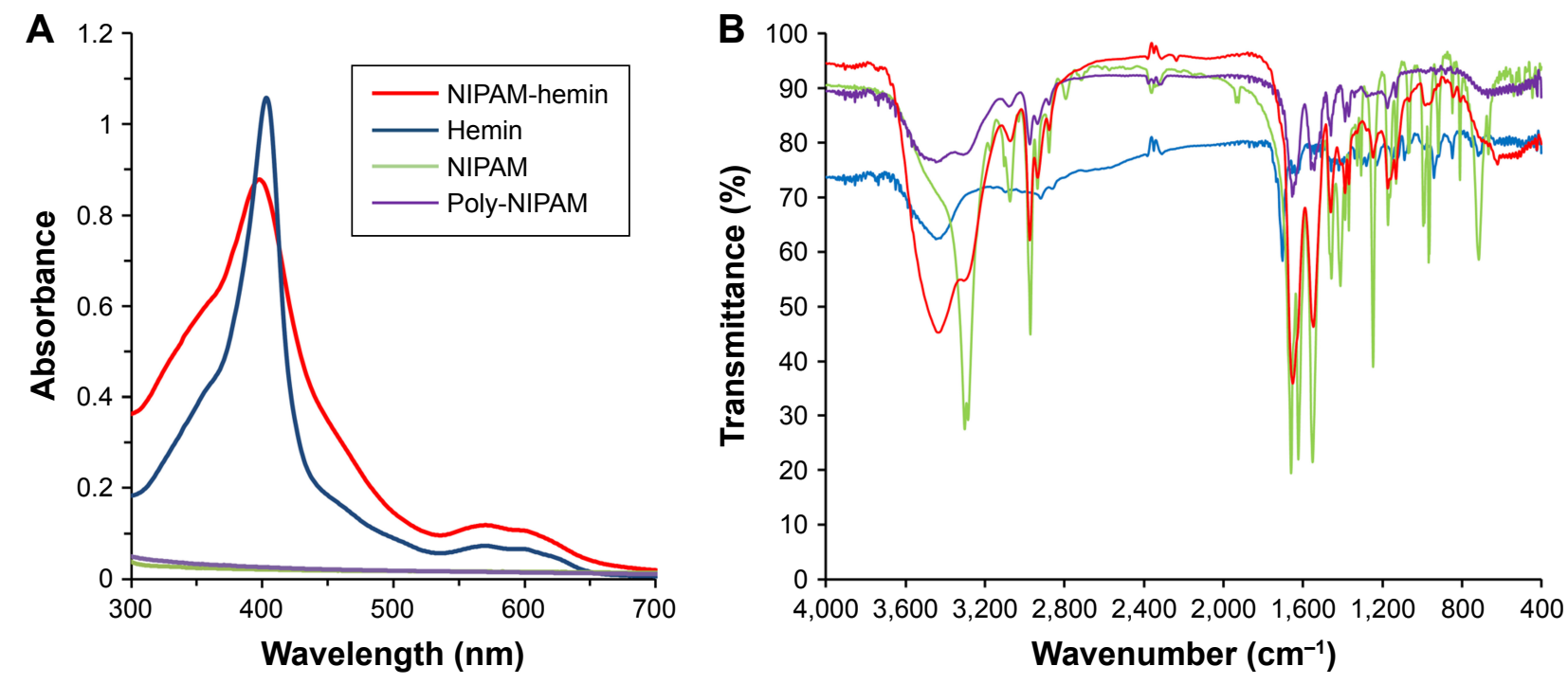

Figure I (A) UV-vis and (B) FTIR spectra for NIPAM-hemin (red), hemin (blue), NIPAM (green), and poly-NIPAM (MW=66,400 Da) (purple). Abbreviations: FTIR, Fourier-transform infrared; NIPAM, N-isopropylacrylamide; hemin, ferriprotoporphyrin IX chloride; MW, molecular weight. 
confirm the limitations of FTIR analysis of NIPAM-hemin, we examined whether a mixture of hemin and poly-NIPAM would show clear peaks of the hemin monomer. The mixture, which contained hemin and NIPAM adjusted to a molar ratio of 1:37, did not show any clear peaks from hemin (Figure S1).

Dynamic light scattering (DLS) measurements were then performed to check for aggregation of NIPAM-hemin in water. No nano-size aggregates of NIPAM-hemin were observed by DLS. In contrast, poly-NIPAM formed particles of around $200 \mathrm{~nm}$ in diameter under the same measurement conditions as those used for NIPAM-hemin, as shown in Figure S2.

\section{NIPAM-hemin showed no cytotoxic effects and induced the production of IFN- $\gamma$ and IL- 6}

The cytotoxic effects of NIPAM-hemin copolymer were first evaluated in 293XL/null and RAW 264 cells using a water-soluble tetrazolium salt-based cell proliferation assay. Figure 2 shows the effect of NIPAM-hemin copolymer concentration on cell proliferation. Tetrazolium salt shows an increased $\mathrm{A}_{450}$ when reduced by dehydrogenases in visible cells. Therefore, the effects of NIPAM-hemin on cell viability were estimated by measuring changes in the $A_{450}$. After incubation for $24 \mathrm{~h}$, the $\mathrm{A}_{450}$ was increased by adding NIPAM-hemin to 293XL/null cells (Figure 2A) and RAW 264 cells (Figure 2B) at a concentration of $0.25,0.5$, and $0.75 \mathrm{mg} / \mathrm{mL}$. However, no significant decrease in the $\mathrm{A}_{450}$ was observed at any concentration. We increased the incubation time to $48 \mathrm{~h}$ to check the cytotoxicity of NIPAM-hemin in RAW 264 cells. No significant decrease was observed after incubation for $48 \mathrm{~h}$ (Figure S3). Using the same experiment, we confirmed that poly-NIPAM showed no cytotoxicity in either of the cell lines (Figure S4). These data showed that NIPAM-hemin has no detectable cytotoxic effects on mammalian cells in vitro.

Scheme 2 shows the experimental flow for the evaluation of the immunostimulatory effects of NIPAM-hemin. First, we investigated the potential immunostimulatory effects of NIPAM-hemin on human PBMCs, which consist of lymphocytes (T cells, B cells, and NK cells), monocytes, and dendritic cells. Figure 3 shows the IFN- $\gamma$, IL- 6 , and IL- $1 \beta$ activity levels in PBMCs treated with NIPAM-hemin copolymer, hemin, NIPAM monomer, or poly-NIPAM. PBMCs stimulated with NIPAM-hemin copolymer or poly-NIPAM produced IFN- $\gamma$ and IL-6. The levels of IFN- $\gamma$ induced by NIPAM-hemin copolymer was almost 11-fold higher than that induced by poly-NIPAM. In contrast, there were no significant differences in IL-6 levels in cells stimulated with NIPAM-hemin copolymer or poly-NIPAM. Neither hemin nor NIPAM monomer induced the production of IFN- $\gamma$ or IL-6.

The IL-1 $\beta$ activity levels were also examined to determine whether NIPAM-hemin activates the NLRP3 inflammasome. Poly-NIPAM induced IL-1 $\beta$ production at $80 \mathrm{pg} / \mathrm{mL}$, whereas NIPAM-hemin induced only $10 \mathrm{pg} / \mathrm{mL}$ IL-1 $\beta$. The IFN- $\alpha$ production levels in all samples were below the detection limit of $7.81 \mathrm{pg} / \mathrm{mL}$. These results indicate that NIPAM-hemin copolymer considerably stimulated the production of IFN- $\gamma$.
A

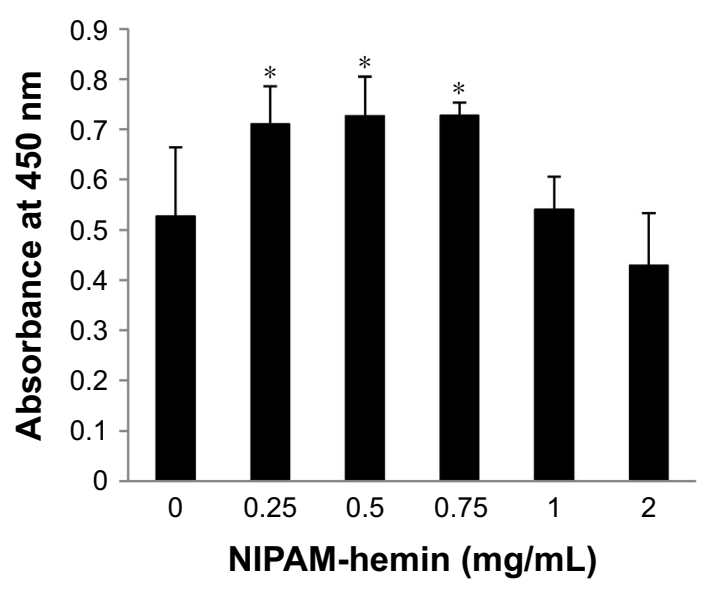

B

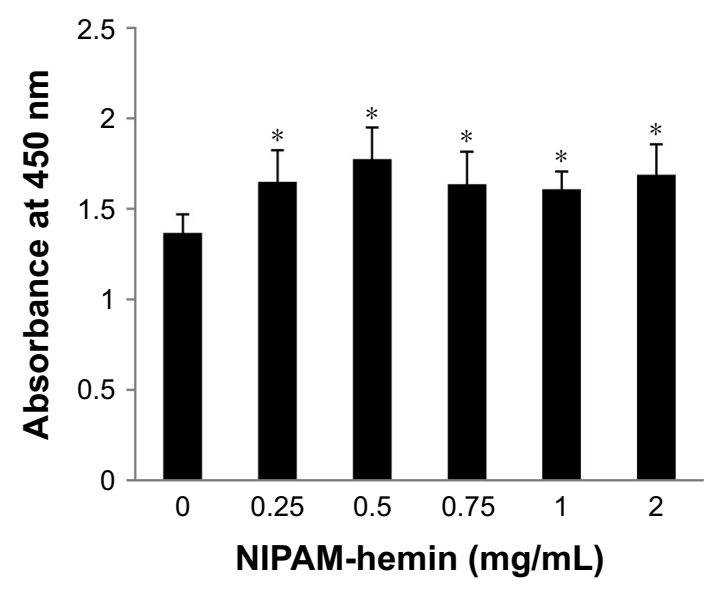

Figure 2 Cytotoxicity assay for NIPAM-hemin in (A) 293XL/null and (B) RAW 264 cells. Cells were incubated with NIPAM-hemin for 24 h in $96-$ well plates; cell viability was estimated by measuring the absorbance at $450 \mathrm{~nm}$.

Notes: Data are expressed as the mean $\pm S D(n=5)$. $* P<0.05$ vs no treatment group.

Abbreviations: NIPAM, $N$-isopropylacrylamide; hemin, ferriprotoporphyrin IX chloride. 

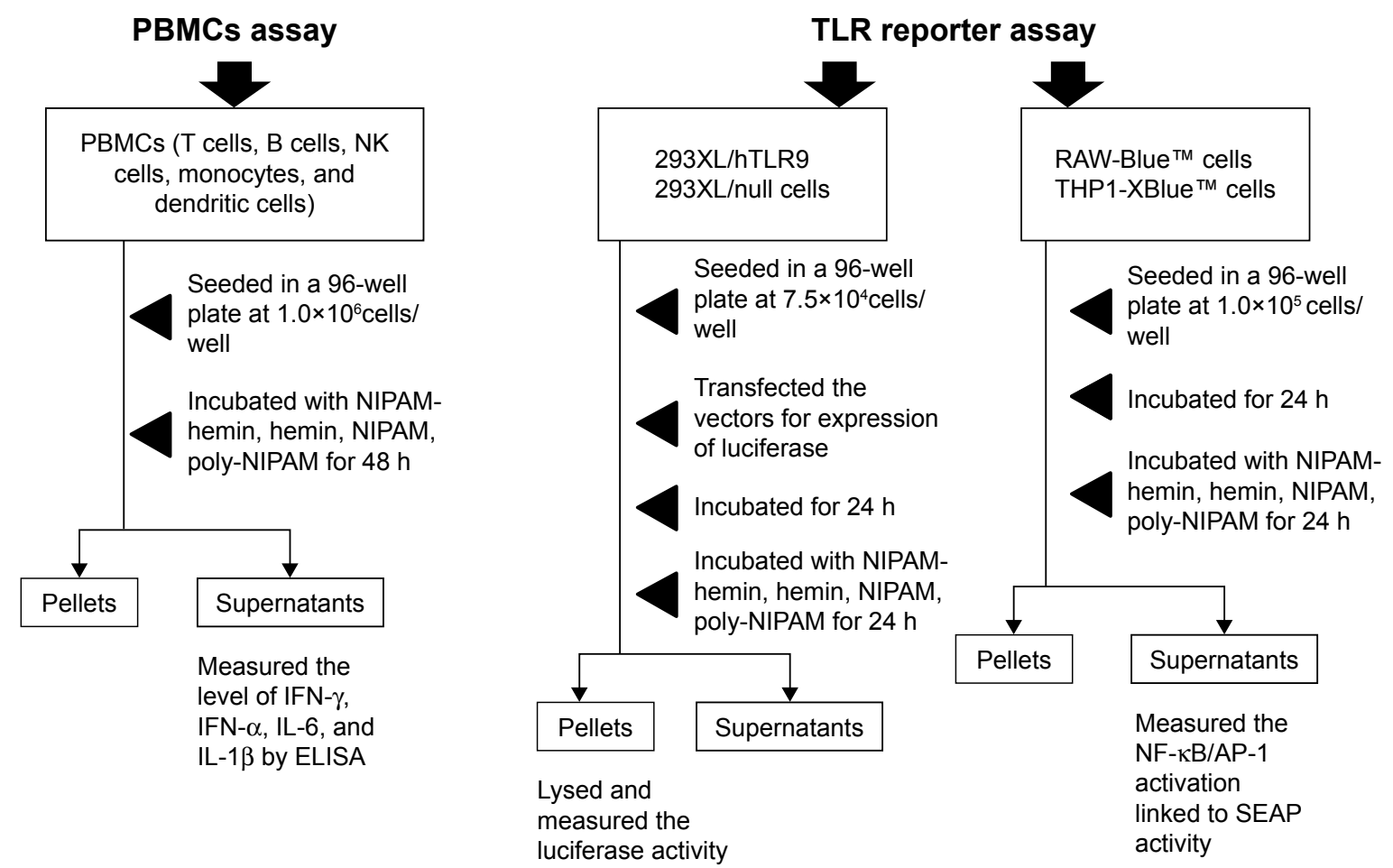

Scheme 2 The evaluation of the immunostimulatory effects of NIPAM-hemin.

Abbreviations: NIPAM, $N$-isopropylacrylamide; hemin, ferriprotoporphyrin IX chloride; IFN- $\gamma$, interferon- $\gamma$; IL, interleukin; NK, natural killer; PBMCs, peripheral blood mononuclear cells; ELISA, enzyme-linked immunosorbent assay; TLRs, toll-like receptors; SEAP, secreted embryonic alkaline phosphatase.

\section{NIPAM-hemin copolymer did not activate TLRs}

As noted above, NIPAM-hemin induced the production IFN- $\gamma$, an indicator of the Th1 immune response. TLRs are often involved in the induction of the Th1 response. ${ }^{10}$ Moreover, the role of TLR9 in the activation of the immune response by natural hemozoin (heme crystal) has been shown in vivo. ${ }^{2}$

Therefore, we examined whether TLR9 was involved in cytokine production using a human TLR9-expressing reporter cell line. Figure 4 shows the results of the NF- $\kappa B$ activation assay. NIPAM-hemin did not induce NF- $\mathrm{KB}$ activation in 293XL/hTLR9, which stably expresses a TLR9, whereas phosphorothioated CpG ODN (2006 PT) induced NF- $\mathrm{KB}$ activation by more than 60 -fold (Figure 4B).

To determine the role of other TLRs in this process, we used two types of immune cell-derived reporter cell lines, RAW-Blue and THP1-XBlue. Both cell lines express most TLRs and show different responses against TLR agonists. RAW-Blue cells expressed all TLRs (TLR1-4 and 6-9) except TLR5 at the mRNA level, and showed a weak response to TLR3 agonists. THP1-XBlue cells expressed all TLRs, including TLR5, at the mRNA level, and showed a weak response to agonists for TLR3, 7, and 9. NIPAM-hemin did not induce NF- $\kappa B$ activation in either cell line (Figure 4C and D). These results indicate that in vitro cytokine production by NIPAM-hemin might be mediated by receptors other than those for the TLR family.

\section{Discussion}

The aim of the present study was to develop a novel hemebased immunostimulator that induces the Th1 immune response. We synthesized a hemin-based copolymer containing hemin and NIPAM at a ratio of 1:37 (hemin:NIPAM). The copolymer had no effects on cell viability. NIPAMhemin induced IFN- $\gamma$ and IL- 6 production in human PBMCs, although neither of the monomers induced the production of these factors.

Alum, emulsions, and lipids are used as vaccine adjuvants for the activation of both humoral immunity and cellular immunity, as summarized in Table $1 .{ }^{11}$ Recently, CpG ODNs were the subject of much interest as a potential new vaccine adjuvant. TLRs, a type of innate immune receptor, play an important role in cellular immunity. ${ }^{10} \mathrm{CpG}$ ODN, a ligand of TLR9, is involved in the production of several cytokines, including IL-6, IL-12, tumor necrosis factor (TNF)- $\alpha$, and IFN- $\gamma .{ }^{12}$ These cytokines activate immune cells and ultimately stimulate the differentiation of $\mathrm{T}$ helper cells into 

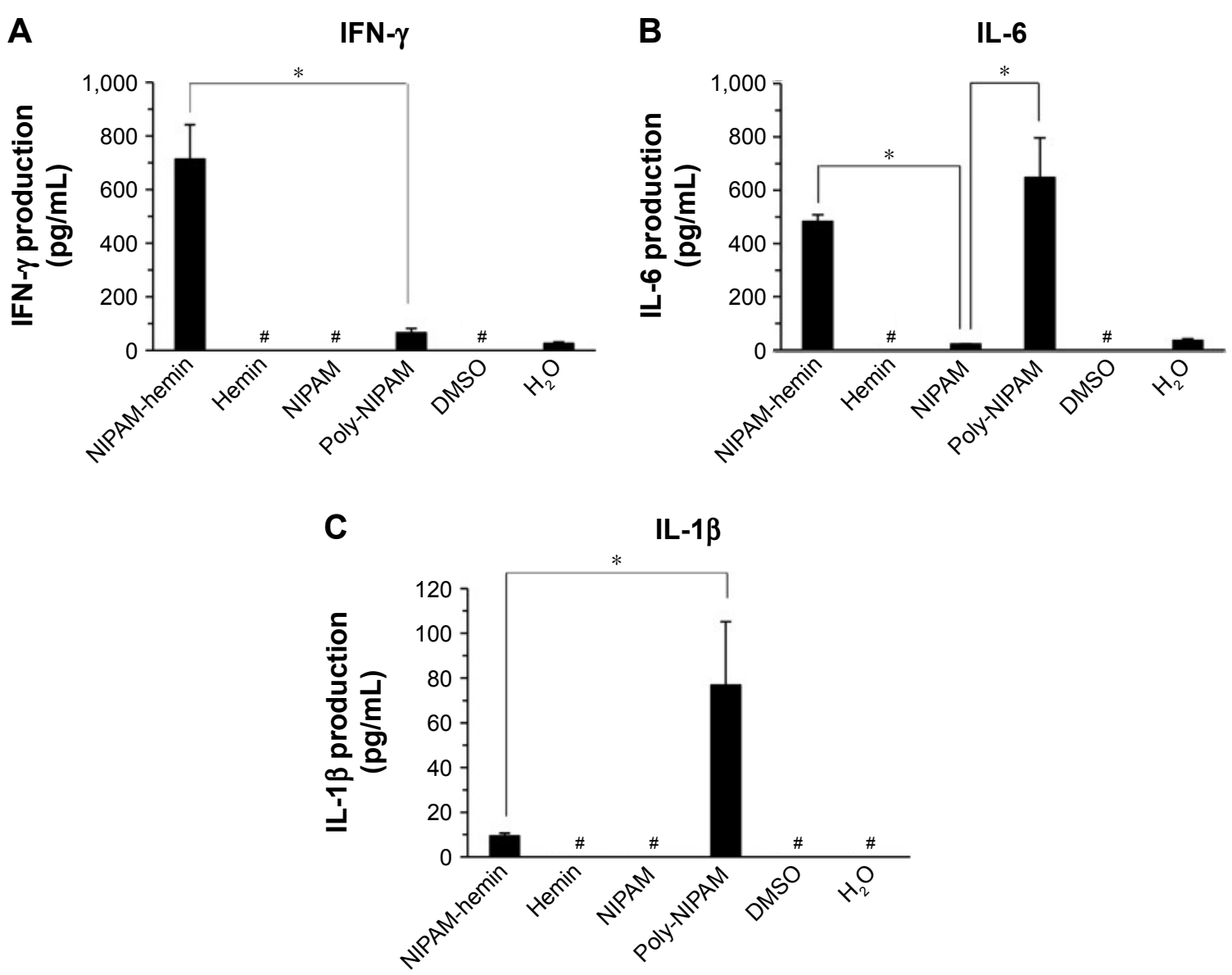

Figure 3 NIPAM-hemin induced the production of IFN- $\gamma$ and IL-6, and had a lesser effect on the induction of IL-I $\beta$, in PBMCs. PBMCs were stimulated with NIPAM-hemin, hemin, NIPAM, or poly-NIPAM (MW=66,400). The levels of (A) IFN- $\gamma,(\mathbf{B})$ IL-6, and (C) IL-I $\beta$ were determined after $48 \mathrm{~h}$. The concentration of each stimulant was $500 \mu g / \mathrm{mL}$. Hemin was dissolved in DMSO, while the other compounds were dissolved in sterilized deionized water.

Notes: Data are expressed as the mean \pm SD $(\mathrm{n}=3)$. ${ }^{* P}<0.05$; ${ }^{\mathrm{IFN}}-\gamma, \mathrm{IL}-6$, and IL-I $\beta$ were produced at levels lower than the detectable $\mathrm{minima}$ of $3.9 \mathrm{I} \mathrm{Pg} / \mathrm{mL}, \mathrm{I} .95 \mathrm{Pg} / \mathrm{mL}$, and $2.34 \mathrm{pg} / \mathrm{mL}$, respectively.

Abbreviations: NIPAM, N-isopropylacrylamide; hemin, ferriprotoporphyrin IX chloride; IFN- $\gamma$, interferon- $\gamma$; IL, interleukin; PBMCs, peripheral blood mononuclear cells; MW, molecular weight; DMSO, dimethyl sulfoxide.

Th1 cells. CpG ODNs can be categorized into two major types: D/A type, and K/B type. D/A type CpG ODNs contain a palindromic $\mathrm{CpG}$ motif and a poly-G tail, and activate plasmacytoid dendritic cells to produce both Type I IFNs (IFN- $\alpha$ and IFN- $\beta$ ) and Type II IFNs (IFN- $\gamma$ ). ${ }^{13} \mathrm{~K} / \mathrm{B}$ type $\mathrm{CpG}$ ODNs comprise multiple $\mathrm{CpG}$ motifs and activate $\mathrm{B}$ cells to produce inflammatory cytokines such as IL-6, IL-12, and TNF- $\alpha$, resulting in antibody production. $.{ }^{14} \mathrm{D} / \mathrm{A}$ type CpG ODNs form higher order structures and, thus, form aggregates and precipitates, thereby hampering their clinical use. ${ }^{15}$ Only type K/B CpGs, which marginally induce type I and type II IFNs, hold promise for clinical applications. In the current study, NIPAM-hemin induced the production of IL-6 and large amounts of IFN- $\gamma$, a type II IFN; however, hemin alone did not induce the production of IFN- $\gamma$ or IL- 6 (Figure 3). The levels of IFN- $\gamma$ and IL-6 induced by 2006 $\mathrm{PT}$, which is known to be a major immunostimulator, were about $300 \mathrm{pg} / \mathrm{mL}$ and $600 \mathrm{pg} / \mathrm{mL}$, respectively (Figure S5). The levels of IL- 6 and IFN- $\gamma$ induced by NIPAM-hemin were comparable to those induced by CpG ODN 2006 PT. IFN- $\gamma$ is the major molecule involved in the differentiation of $\mathrm{T}$ helper cells to Th1 cells, resulting in IgG2 production. Therefore, we expected NIPAM-hemin to be a successful Th1 adjuvant.

NIPAM-hemin did not decrease cell viability, even though hemin is known to be toxic to several cell types. ${ }^{16,17}$ One of the causes of hemin-induced cytotoxicity is the hydrophobicity of the heme group, which interacts with lipids and leads to peroxidation. ${ }^{16}$ NIPAM is soluble and binds to the non-soluble hemin to form a soluble copolymer. Fang et al ${ }^{18}$ demonstrated that soluble pegylated hemin does not show cytotoxic effects in vitro. Therefore, the non-toxicity of NIPAM-hemin in vitro can be explained by the reduced hydrophobicity of the polymer. 
A

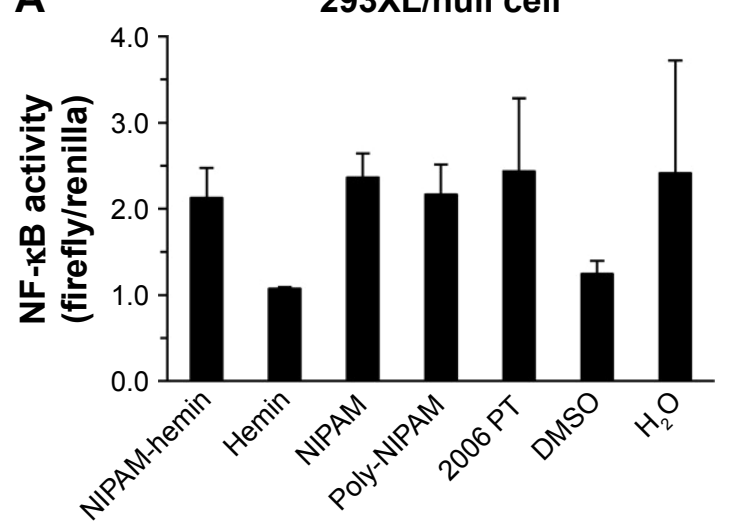

C

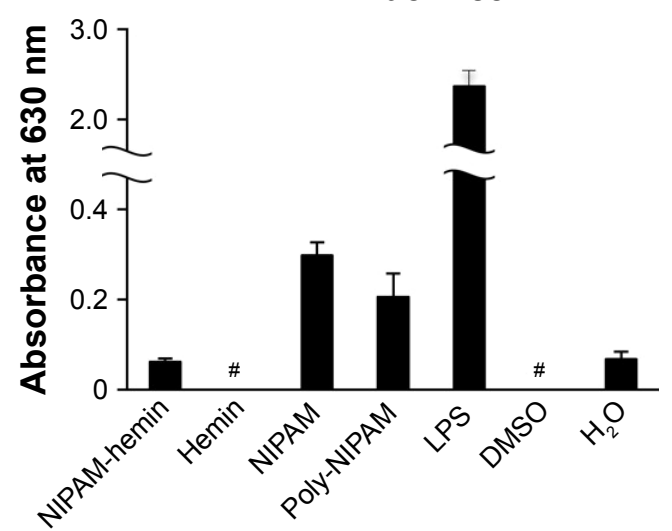

B

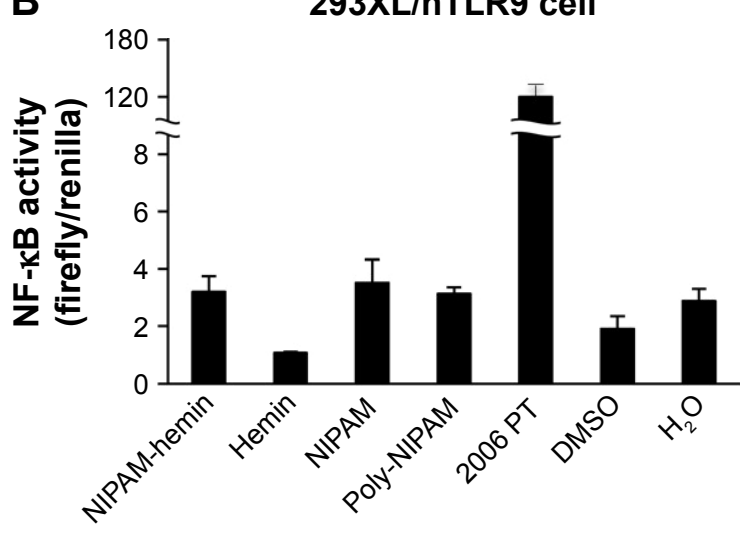

D

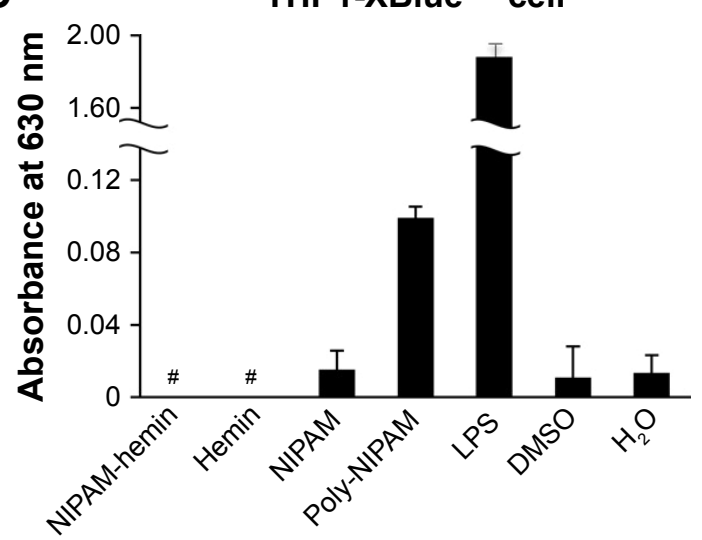

Figure 4 NIPAM-hemin did not induce NF-KB signaling via most TLRs in reporter cells. (A) 293XL/null cells, (B) 293XL/hTLR9 cells, (C) RAW-Blue cells, and (D) THPIXBlue cells were incubated with $500 \mu \mathrm{g} / \mathrm{mL}$ NIPAM-hemin, hemin, NIPAM, or poly-NIPAM (MW=66,400 Da). LPS (500 $\mu \mathrm{g} / \mathrm{mL})$ or 2006 PT (0.5 $\mu$ M), agonists for TLR4 and TLR9, respectively, were added to the cells as positive controls. Hemin was dissolved in DMSO, while the other compounds were dissolved in sterilized deionized water. Notes: Data are expressed as the mean $\pm S D(n=5)$. "Absorbance not detected.

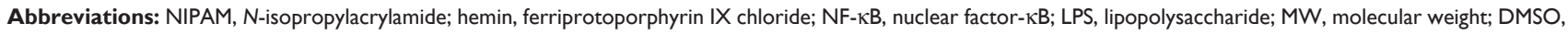
dimethyl sulfoxide.

$\beta$-hematin is chemically synthesized from hemin. Natural hemozoin consists of a heme dimer. $\beta$-hematin induces the production of cytokines such as IL- 6 , IL- $1 \alpha$, and IL- $1 \beta$ in vivo. ${ }^{19}$ Recent studies have suggested that $\beta$-hematin activates the NLRP3 inflammasome, showing effects similar to those of particles such as alum, asbestos, and silica. ${ }^{20-22}$ The NLRP3 inflammasome plays an important role in the production of the inflammatory cytokine IL- $1 \beta .{ }^{23}$ IL- $1 \beta$ is known to be a major inducer of IL-6 production in monocytes. ${ }^{24}$ These studies have also indicated that the activation of the NLRP3 inflammasome could be a common immune response induced by particles or crystals. Conversely, Coban et $\mathrm{al}^{2}$ reported that

Table I The type of major adjuvants used for the development of vaccines

\begin{tabular}{llll}
\hline Type & Components & $\begin{array}{l}\text { Type of immunity } \\
\text { induced }\end{array}$ & Vaccines used \\
\hline Alum & Aluminum phosphate or hydroxide & Th2 & HAV, HBV, HPV, diphtheria, tetanus \\
MF59 & Squalene based oil-in-water emulsions & ThI or Th2 & H5NI pandemic influenza, HINI influenza vaccine \\
AS03 & Squalene based oil-in-water emulsions, & Thl or Th2 & H5NI pandemic influenza, HINI influenza vaccine \\
Virosomes & $\begin{array}{l}\text { Q-tocopherol } \\
\text { Viral envelope possessing membrane }\end{array}$ & Thl or Th2 & Influenza virus, HAV \\
AS04 & lipids and viral glycoproteins & ThI or Th2 & HPV vaccine, HBV vaccine \\
\hline
\end{tabular}

Abbreviations: MPL, monophosphoryl lipid A; ThI, type I T helper; Th2, type 2 T helper; HAV, hepatitis A virus; HBV, hepatitis B virus; HPV, human papilloma virus. 
the adjuvant effect of $\beta$-hematin is independent of the NLRP3 inflammasome. The implications of the effect of $\beta$-hematin on the activation of the NLRP3 inflammasome are not yet fully understood. In this study, poly-NIPAM (MW=66,400 Da), a polymer of NIPAM, formed particles of around $200 \mathrm{~nm}$ in size and stimulated IL- $1 \beta$ production $(80 \mathrm{pg} / \mathrm{mL})$ (Figure 3). Gómez et $\mathrm{al}^{25}$ reported that silica particles of around $200 \mathrm{~nm}$ in size $(10 \mu \mathrm{g} / \mathrm{mL})$, another activator of the NLRP3 inflammasome, also induced the production of IL- $1 \beta$ $(200-500 \mathrm{pg} / \mathrm{mL})$ in PBMCs. On the other hand, we observed no particle formation by NIPAM-hemin, and reduced production of IL-1 $1 \beta(10 \mathrm{pg} / \mathrm{mL})$. These results suggest that the induction of IL- 6 and IFN- $\gamma$ in PBMCs by NIPAM-hemin occurs independent of the NLRP3 inflammasome.

The activation of natural hemozoin is mediated by TLR9, and is dependent on MyD88. Natural hemozoin induces the production of monocyte chemoattractant protein 1 (MCP-1), TNF- $\alpha$, IL-12, p40, and IL-6 in spleen cells via TLR9 mediation. ${ }^{26}$ Moreover, Temizoz et al ${ }^{27}$ reported that TLR9 and stimulator of interferon gene (STING) agonists induce IL-12 and IFN- $\alpha$, respectively, which synergistically regulate IFN- $\gamma$ production in NK cells in human PBMCs. ${ }^{27}$ NIPAM-hemin also induces the production of IFN- $\gamma$; thus, we expected to observe NF-KB activation by NIPAM-hemin in TLR9-expressing cells. However, our study demonstrated that NIPAM-hemin did not activate NF- $\kappa B$ via any TLRs, including TLR9, in vitro (Figure 4). Although hemin does not exhibit an adjuvant effect, it binds to the extracellular domains of recombinant human TLR9, and causes a conformational change. ${ }^{2}$ Moreover, TLR9 forms a symmetrical TLR-CpG ODN complex with 2:2 stoichiometry, in which each dimer binds a CpG ODN. ${ }^{7}$ Based on these previous reports, we predicted that the binding of ligand molecules to each dimer of TLR9 might be necessary for TLR9 activation. The mechanism of TLR9 activation by hemozoin remains unclear. However, hemozoin consists of a heme dimer; thus, two hemes will be closely situated. Consequently, multiple adjacent heme molecules might be important for the formation of the active form of TLR9. ICP-OES measurements showed that the copolymer contained a low ratio of hemin to NIPAM. It is unlikely that multiple hemins would be in close proximity to each other, as the hemin concentration in the polymer was low. This may explain why we did not observe NF- $\kappa B$ activation via TLR9 by NIPAM-hemin. However, $\beta$-hematin has an adjuvant effect independent of TLR9, as does NIPAM-hemin; therefore, future investigations are needed to assess the IFN- $\gamma$ production pathway induced by NIPAM-hemin.
In addition to IFN- $\gamma$ production, it was clear that NIPAMhemin stimulated the production of IL- 6 , which stimulates B cell maturation. ${ }^{28}$ Further studies are needed to determine how NIPAM-hemin acts as an adjuvant, for example, by injecting it into mice along with an antigen, followed by measuring the amount of $\operatorname{IgG}$ isotypes (IgG2a or $\operatorname{IgG} 1)$.

\section{Conclusion}

In this work, we synthesized a hemin-containing immunostimulator by radical polymerization of hemin with NIPAM. Importantly, NIPAM-hemin does not affect cell viability, and induced the production of large amounts of IFN- $\gamma$ in human PBMCs. The NIPAM-hemin copolymer shows potential as a new adjuvant.

\section{Acknowledgments}

The authors would like to thank Ms Satomi Kohara, Ms Satomi Magae, Ms Yuko Matsumoto, and Mr Kazuya Tsukagoshi for technical assistance with the experiments. We are deeply grateful to Dr Ebara (NIMS, Japan) who provided poly-NIPAM, and to Dr Satoshi Kawada and Mr Akira Ishitoya in materials analysis station (NIMS, Japan) for ICP-OES measurement.

This work was conducted in NIMS Molecule \& Material Synthesis platform, supported by Nanotechnology Platform Program of the Ministry of Education, Culture, Sports, Science and Technology (MEXT), Japan. This work was supported by Japan Society for the Promotion of Science Kakenhi grant number 15K06589. We thank Editage, a division of Cactus Communications, for editing language service.

\section{Disclosure}

The authors report no conflicts of interest in this work.

\section{References}

1. Lindblad EB. Aluminium compounds for use in vaccines. Immunol Cell Biol. 2004;82(5):497-505.

2. Coban C, Igari Y, Yagi M, et al. Immunogenicity of whole-parasite vaccines against plasmodium falciparum involves malarial hemozoin and host TLR9. Cell Host Microbe. 2010;7(1):50-61.

3. Slater AF, Swiggard WJ, Orton BR, et al. An iron-carboxylate bond links the heme units of malaria pigment. Proc Natl Acad Sci US A. 1991;88(2):325-329.

4. Onishi M, Kitano M, Taniguchi K, et al. Hemozoin is a potent adjuvant for hemagglutinin split vaccine without pyrogenicity in ferrets. Vaccine. 2014;32(25):3004-3009.

5. Uraki R, Das SC, Hatta M, et al. Hemozoin as a novel adjuvant for inactivated whole virion influenza vaccine. Vaccine. 2014;32(41):5295-5300.

6. Coban C, Yagi M, Ohata K, et al. The malarial metabolite hemozoin and its potential use as a vaccine adjuvant. Allergol Int. 2010;59(2):115-124.

7. Ohto U, Shibata T, Tanji H, et al. Structural basis of $\mathrm{CpG}$ and inhibitory DNA recognition by Toll-like receptor 9. Nature. 2015;520(7549): $702-705$. 
8. Gao Y, Chen J. Redox reaction of hemin-immobilized polyallylaminepolystyrene latex suspensions. J Electroanal Chem. 2005;578(1): 129-136.

9. Jadhav SA, Brunella V, Miletto I, Berlier G, Scalarone D. Synthesis of poly(N-isopropylacrylamide) by distillation precipitation polymerization and quantitative grafting on mesoporous silica. J Appl Polym Sci. 2016;133(44):44181.

10. Netea MG, Van der Meer JW, Sutmuller RP, Adema GJ, Kullberg BJ. From the Th1/Th2 paradigm towards a toll-like receptor/T-helper bias. Antimicrob Agents Chemother. 2005;49(10):3991-3996.

11. Lee S, Nguyen MT. Recent advances of vaccine adjuvants for infectious diseases. Immune Netw. 2015;15(2):51-57.

12. Chu RS, Targoni OS, Krieg AM, Lehmann PV, Harding CV. CpG oligodeoxynucleotides act as adjuvants that switch on T helper 1 (Th1) immunity. J Exp Med. 1997;186(10):1623-1631.

13. Krug A, Rothenfusser S, Hornung V, et al. Identification of CpG oligonucleotide sequences with high induction of IFN-alpha/beta in plasmacytoid dendritic cells. Eur J Immunol. 2001;31(7):2154-2163.

14. Hartmann G, Weeratna RD, Ballas ZK, et al. Delineation of a CpG phosphorothioate oligodeoxynucleotide for activating primate immune responses in vitro and in vivo. J Immunol. 2000;164(3): 1617-1624.

15. Kerkmann M, Costa LT, Richter C, et al. Spontaneous formation of nucleic acid-based nanoparticles is responsible for high interferon- $\alpha$ induction by CpG-A in plasmacytoid dendritic cells. J Biol Chem. 2005;280(9):8086-8093.

16. Higdon AN, Benavides GA, Chacko BK, et al. Hemin causes mitochondrial dysfunction in endothelial cells through promoting lipid peroxidation: the protective role of autophagy. Am J Physiol Heart Circ Physiol. 2012;302(7):H1394-H1409.

17. Zhou YF, Zhang $C$, Yang $G$, et al. Hepcidin protects neuron from hemin-mediated injury by reducing iron. Front Physiol. 2017;8:332.
18. Fang J, Qin H, Seki T, et al. Therapeutic potential of pegylated hemin for reactive oxygen species-related diseases via induction of heme oxygenase-1: results from a rat hepatic ischemia/reperfusion injury model. J Pharmacol Exp Ther. 2011;339(3):779-789.

19. Griffith JW, Sun T, McIntosh MT, Bucala R. Pure hemozoin is inflammatory in vivo and activates the NALP3 inflammasome via release of uric acid. J Immunol. 2009;183(8):5208-5220.

20. Duewell P, Kono H, Rayner KJ, et al. NLRP3 inflammasomes are required for atherogenesis and activated by cholesterol crystals. Nature. 2010;464(7293):1357-1361.

21. Hornung V, Bauernfeind F, Halle A, et al. Silica crystals and aluminum salts activate the NALP3 inflammasome through phagosomal destabilization. Nat Immunol. 2008;9(8):847-856.

22. Kusaka T, Nakayama M, Nakamura K, Ishimiya M, Furusawa E, Ogasawara K. Effect of silica particle size on macrophage inflammatory responses. PLoS One. 2014;9(3):e92634.

23. He Y, Hara H, Núñez G. Mechanism and regulation of NLRP3 inflammasome activation. Trends Biochem Sci. 2016;41(12):1012-1021.

24. Tosato G, Jones KD. Interleukin-1 induces interleukin-6 production in peripheral blood monocytes. Blood. 1990;75(6):1305-1310.

25. Gómez DM, Urcuqui-Inchima S, Hernandez JC. Silica nanoparticles induce NLRP3 inflammasome activation in human primary immune cells. Innate Immun. 2017;23(8):697-708.

26. Coban C, Ishii KJ, Kawai T, et al. Toll-like receptor 9 mediates innate immune activation by the malaria pigment hemozoin. J Exp Med. 2005; 201(1):19-25.

27. Temizoz B, Kuroda E, Ohata K, et al. TLR9 and STING agonists synergistically induce innate and adaptive type-II IFN. Eur J Immunol. 2015;45(4):1159-1169.

28. Rincón M, Anguita J, Nakamura T, Fikrig E, Flavell RA. Interleukin (IL)-6 directs the differentiation of IL-4-producing CD4+ T cells. J Exp Med. 1997;185(3):461-469. 


\section{Supplementary materials}

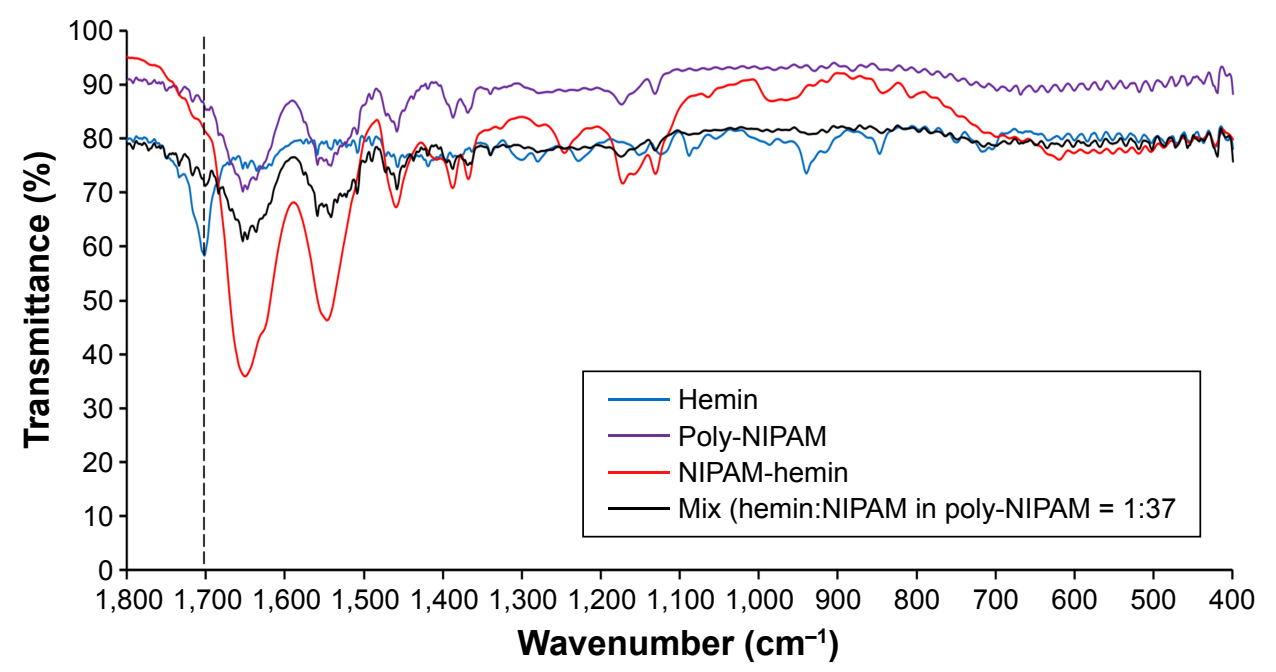

Figure SI FTIR spectra of a mixture of hemin monomer and poly-NIPAM (MW=66,400 Da).

Notes: The molar ratio of hemin and NIPAM in poly-NIPAM was adjusted to 1:37. The broken line shows the peaks attributed to the hemin monomer. Abbreviations: FTIR, Fourier-transform infrared; hemin, ferriprotoporphyrin IX chloride; MW, molecular weight; NIPAM, N-isopropylacrylamide.

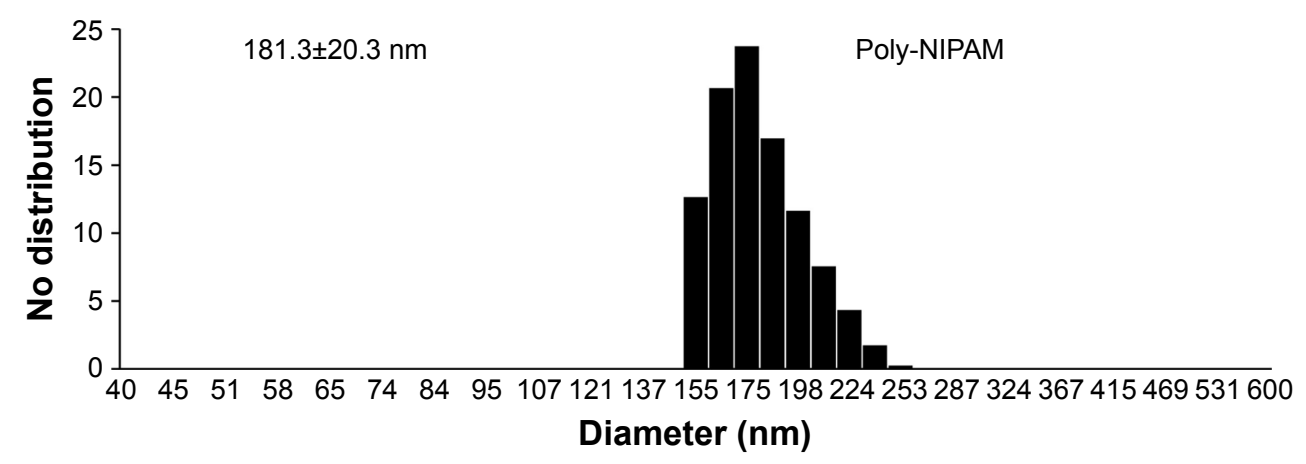

Figure S2 Poly-NIPAM (MW $=66,400 \mathrm{Da})$ formed particles at $37^{\circ} \mathrm{C}$ in water.

Note: Particle size was determined by DLS measurement.

Abbreviations: NIPAM, N-isopropylacrylamide; MW, molecular weight; DLS, dynamic light scattering.

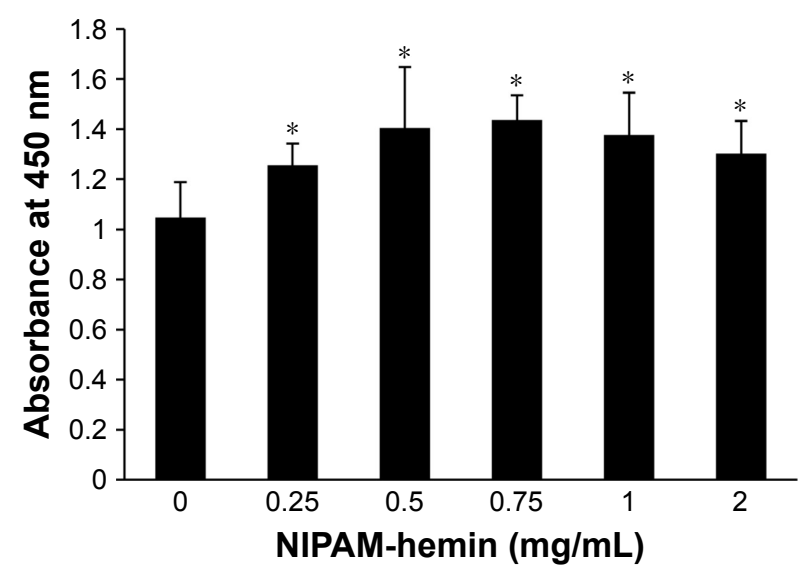

Figure S3 NIPAM-hemin was not cytotoxic to RAW 264 cells after incubation for 48 h. Cells were incubated with NIPAM-hemin for 48 h in 96 -well plates; cell viability was estimated by measuring the absorbance at $450 \mathrm{~nm}$.

Notes: Data are expressed as the mean $\pm S D(n=5) . * P<0.05$ vs no treatment group.

Abbreviations: NIPAM, N-isopropylacrylamide; hemin, ferriprotoporphyrin IX chloride. 

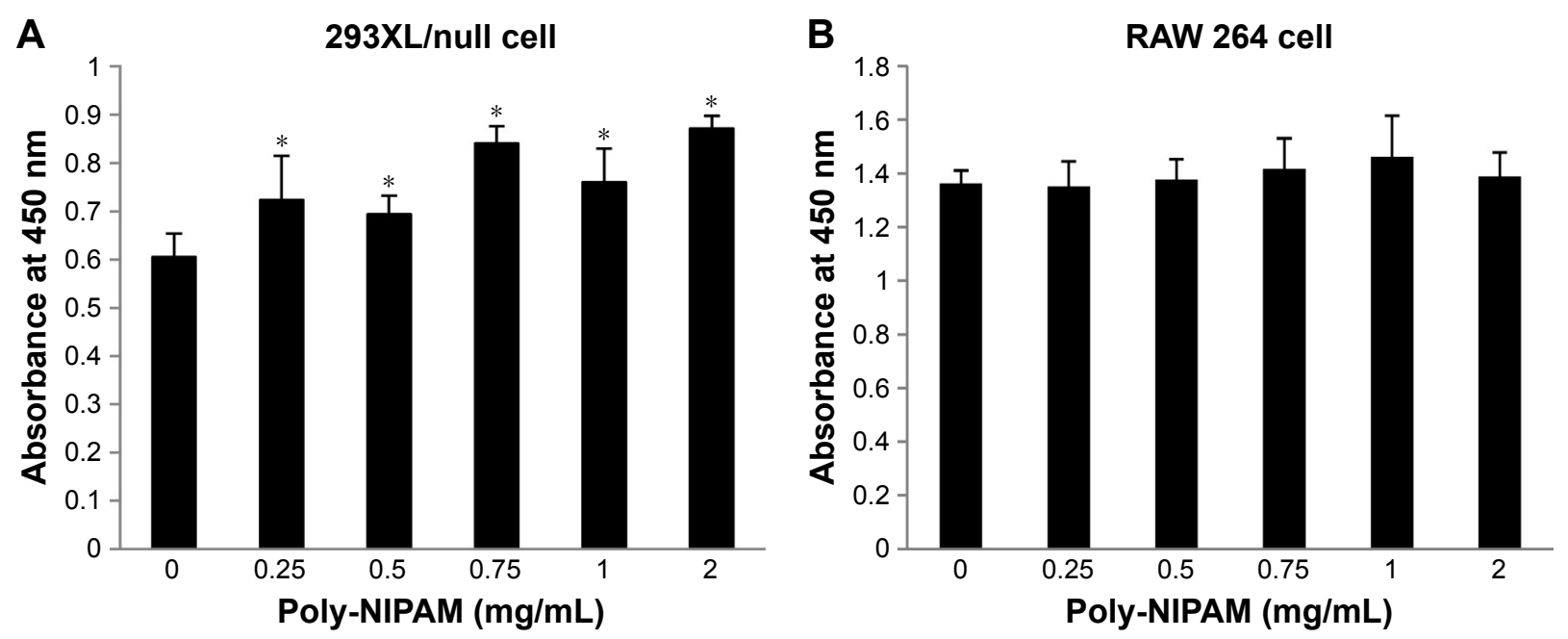

Figure S4 Poly-NIPAM was not cytotoxic to (A) 293XL/null and (B) RAW 264 cells. Cells were incubated with poly-NIPAM for $24 \mathrm{~h}$ in a 96 -well plate and cell viability was estimated by measuring the absorbance at $450 \mathrm{~nm}$.

Notes: Data are expressed as the mean \pm SD $(n=5) . * P<0.05$ vs no treatment group.

Abbreviation: NIPAM, N-isopropylacrylamide.
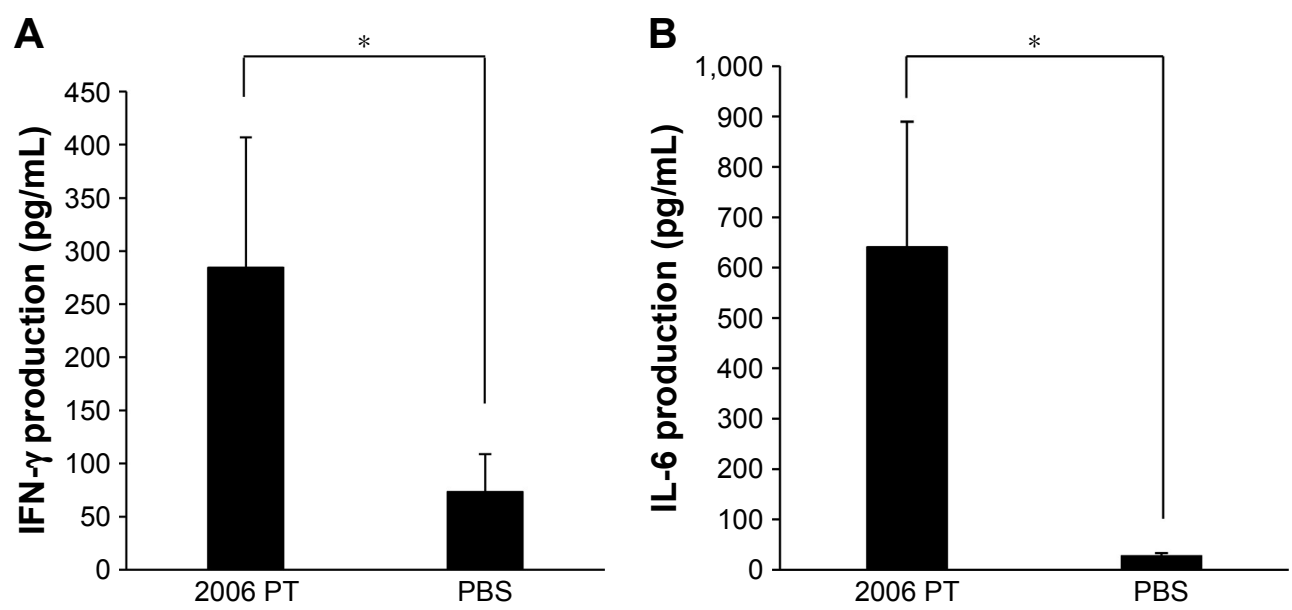

Figure S5 The levels of IFN- $\gamma$ and IL-6 production in PBMCs after incubation with 2006 PT. PBMCs were stimulated with 2006 PT (0.5 $\mu$ M); the amounts of (A) IFN- $\gamma$ and (B) IL-6 were determined after incubation for $48 \mathrm{~h}$.

Notes: Data are expressed as the mean \pm SD ( $n=6-9)$. $* P<0.05$.

Abbreviations: IFN- $\gamma$, interferon- $\gamma$; IL, interleukin; PBMCs, peripheral blood mononuclear cells.

\section{Publish your work in this journal}

The International Journal of Nanomedicine is an international, peerreviewed journal focusing on the application of nanotechnology in diagnostics, therapeutics, and drug delivery systems throughout the biomedical field. This journal is indexed on PubMed Central,

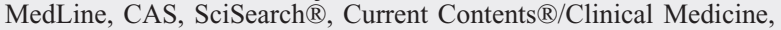

Journal Citation Reports/Science Edition, EMBase, Scopus and the Elsevier Bibliographic databases. The manuscript management system is completely online and includes a very quick and fair peer-review system, which is all easy to use. Visit http://www.dovepress.com/ testimonials.php to read real quotes from published authors. 